\title{
Treatment of chronic heart failure with pirbuterol: acute haemodynamic responses
}

\author{
J R DAWSON, R CANEPA-ANSON, P KUAN, N H G WHITAKER, J CARNIE, C WARNES, \\ S R REUBEN, P A POOLE-WILSON, G C SUTTON
}

\begin{abstract}
Fifty-nine patients with severe chronic heart failure were given pirbuterol, a beta agonist with vasodilator and positive inotropic properties. The acute haemodynamic responses to both single (20 patients) and incremental doses (39 patients) were measured. Pirbuterol increased cardiac index and reduced left ventricular filling pressure and systemic vascular resistance with only small changes in heart rate and blood pressure. Maximal effects were observed at an average of 170 minutes after a single oral dose of pirbuterol. In the incremental dose studies the plasma pirbuterol concentration was found to increase with increasing doses and was related to the magnitude of the haemodynamic response. Pirbuterol was well tolerated, and no drug-related side effects were recorded.

Oral pirbuterol clearly improved pump performance in these patients, the haemodynamic changes being consistent with vasodilatation as the dominant mechanism rather than a direct inotropic effect.
\end{abstract}

\section{Introduction}

Both vasodilator ${ }^{12}$ and positive inotropic drugs ${ }^{3-5}$ have been shown to produce short-term benefit in chronic heart failure refractory to conventional treatment with digitalis and diuretics. More recent studies have emphasised the advantages of the drug combination. ${ }^{6}{ }^{7}$ Hence the ideal drug for treatment would be an oral agent possessing both properties. Pirbuterol is a recently developed sympathomimetic amine structurally similar to salbutamol. In-vitro experiments with animal tissues ${ }^{8}$ suggest that its principal cardiovascular effect is relaxation of vascular smooth muscle causing vasodilatation (beta ${ }_{2}$ agonist effect), while in-vivo experiments in animals ${ }^{9}$ indicate that the drug also exerts a positive inotropic action (beta ${ }_{1}$ effect). Initial studies in man suggested that pirbuterol may be advantageous in chronic congestive heart failure. ${ }^{10} 11$

We have studied a large number of patients in three different centres. We investigated the time course of the acute haemodynamic response to two different doses of oral pirbuterol and to

Hillingdon Hospital, Uxbridge, Middlesex

J R DAWSON, MRCP, research registrar in cardiology (now registrar in cardiology, St Thomas's Hospital, London)

N H G WHITAKER, MRCP, research registrar

G C SUTTON, MD, FRCP, consultant physician

National Heart Hospital and Cardiothoracic Institute, London

R CANEPA-ANSON, MRCP, senior registrar in cardiology and fellow in cardiothoracic medicine.

C WARNES, MRCP, registrar in cardiology

P A POOLE-WILSON, MD, MRCP, reader in cardiology and honorary consultant cardiologist

East Birmingham Hospital, Birmingham B9 5ST

$P$ KUAN, MD, research registrar in cardiology

J CARNIE, MB, FFA RCS, senior registrar in anaesthetics

S R REUBEN, DPHIL, MRCP, consultant cardiologist incremental doses. The relation between the haemodynamic responses and the plasma concentration was examined to establish its clinical pharmacology.

\section{Patients and methods}

Fifty-nine patients with chronic heart failure entered the study, which was approved by the hospitals' ethics committees. There were 46 men and 13 women with an average age of 62 years (range 42-71 years). Fifteen of the patients were confined to bed by extreme dyspnoea (class 4 NYHA), while the remainder could walk only short distances (class 3 NYHA). There was radiological evidence of cardiomegaly and pulmonary venous congestion in all patients despite large doses of frusemide (average daily dose $180 \mathrm{mg}$ ). Twenty-six patients were taking digoxin.

The aetiology of heart failure was coronary artery disease in all patients other than nine who had congestive cardiomyopathy of unknown aetiology, three who had alcohol-induced cardiomyopathy, and one who had aortic regurgitation. Fifty-three patients were in sinus rhythm, while six were in atrial fibrillation. Pirbuterol was administered by mouth either as a single dose (group 1) or in incremental doses (groups 2 and 3). In the first group 10 patients received $10 \mathrm{mg}$ and a further 10 received $20 \mathrm{mg}$. In group 2 the 26 patients received incremental doses at 90 -minute intervals of 10,10 , and $20 \mathrm{mg}$ to give cumulative doses of 10,20 , and $40 \mathrm{mg}$. The 13 patients in group 3 received incremental doses at 90 -minute intervals to give cumulative doses of $7 \cdot 5,15$, and $30 \mathrm{mg}$.

All patients were studied without premedication while resting in bed. Each study began in the morning after a light breakfast. Right atrial, pulmonary artery, and wedge pressures were measured with a Swan-Ganz flow-directed triple-lumen catheter (CVI model No 600-017, Edwards Labs model No 93A $1317 \mathrm{~F}$ ) positioned in the pulmonary artery. The mid-chest was used as the zero reference point. Either the wedge pressure or pulmonary artery diastolic pressure was used as an indirect assessment of left ventricular filling pressure. Cardiac output was measured in triplicate by the thermodilution technique (CVI model No 600, Edwards Labs model No 9510-A). Blood pressure was measured with either a sphygmomanometer (groups 1 and 3) or an indwelling radial artery cannula (group 2). Mean blood pressure was calculated as the diastolic pressure plus a third of the pulse pressure (groups 1 and 3 ) or derived from an electronically integrated record (group 2). Heart rate was obtained from an electrocardiogram and was averaged over 20 beats.

In group 1 measurements were made at rest during a 30-minute control period and at 30-minute intervals for six hours after the single oral dose of pirbuterol. In groups 2 and 3 measurements were made during a similar control period, at 90 minutes after each incremental dose, and at 90 and 180 minutes after the final dose. Systemic vascular resistance (dyne $\mathrm{s} \mathrm{cm}^{-5}$ ) was calculated as: (mean blood pressure mean right atrial pressure)/cardiac output.

In 29 patients blood samples for plasma pirbuterol assay were taken at the time of each set of haemodynamic measurements. Assays were performed by gas chromatographic mass spectrometry. ${ }^{12}$ The assay measures the concentration of free unbound pirbuterol in the plasma. Results are expressed as means \pm SEM. Differences between means were compared using Student's $t$ test for paired data.

\section{Results}

Group 1 (single-dose studies)-The magnitude of the effects on haemodynamic variables of 10 and $20 \mathrm{mg}$ doses of pirbuterol was not significantly different and the data for all 20 patients were therefore combined. Figure 1 shows the changes with time in cardiac index, left ventricular filling pressure, and systemic vascular resistance. The 
average time from pirbuterol administration to maximal changes in cardiac index was 170 minutes, but wide variations among patients were observed (range 30-270 minutes). Table I shows the changes in all measured and calculated haemodynamic variables at the time of maximal cardiac index.

Group 2 (high-dose incremental studies)-Maximal changes in cardiac index were recorded between 180 and 360 minutes (fig 2). Table II gives the changes in all measured and calculated haemodynamic variables. There were no significant differences between measurements
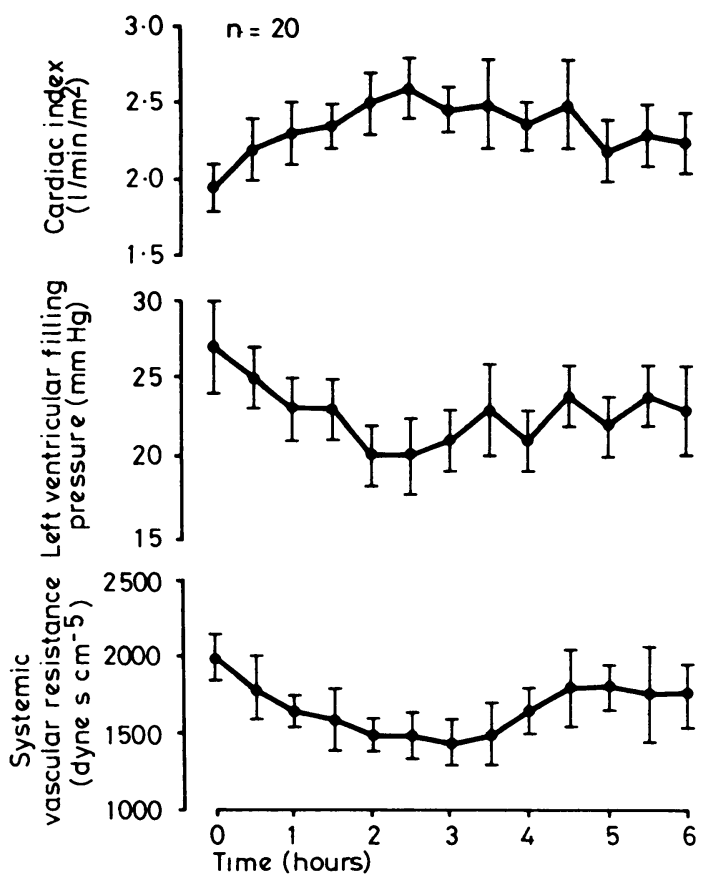

FIG 1-Changes with time in cardiac index, left ventricular filling pressure, and systemic vascular resistance in 20 patients (group 1) given single oral dose of pirbuterol. (Plots are means \pm SEM).

TABLE I-Values for all measured and calculated haemodynamic variables in 20 patients (group 1) receiving single oral dose of pirbuterol during control period and at time of maximum change in cardiac index (means $\pm S E M$ )

\begin{tabular}{|c|c|c|c|}
\hline & & Control & $\underset{\text { effect }}{\text { Maximum }}$ \\
\hline 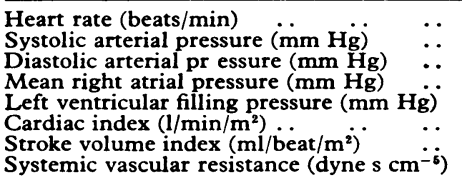 & $\begin{array}{l}\cdots \\
\because \\
\because \\
\cdots \\
\cdots\end{array}$ & $\begin{aligned} 94 & \pm 5 \\
112 & \pm 5 \\
73 & \pm 3 \\
9 & \pm 2 \\
27 & \pm 3 \\
1 \cdot 9 & \pm 0 \cdot 1 \\
22 & \pm 2 \\
1895 & \pm 130\end{aligned}$ & $\begin{aligned} & 96 \pm 4 \\
& 112 \pm 4 \\
& 71 \pm 2 \\
& 7 \pm 2 * \\
& 20 \pm 3^{*} \\
& 2 \cdot 5 \pm 0 \cdot 2 \dagger \\
& 27 \pm 3 \dagger \\
& 1555 \pm 115 \dagger\end{aligned}$ \\
\hline
\end{tabular}

${ }^{*} \mathrm{p}<0.01 . \quad+\mathrm{p}<0.001$ at 180,270 , and 360 minutes in any haemodynamic variable except heart rate and systemic vascular resistance $(p<0.01)$.

Group 3 (low-dose incremental studies)-Maximal changes if cardiac index were recorded at 180 or 270 minutes. There was no significant difference between the measurements of any haemodynamb variable at 180 and 270 minutes (table III).

TABLE III-Values for all haemodynamic variables with time and incremental doses in 13 patients (group 3) (means $\pm S E M$ )

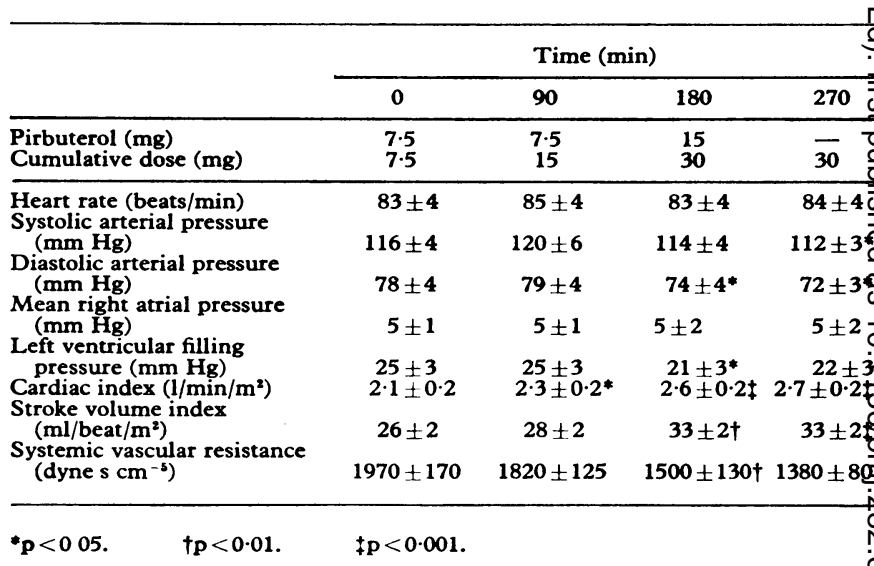
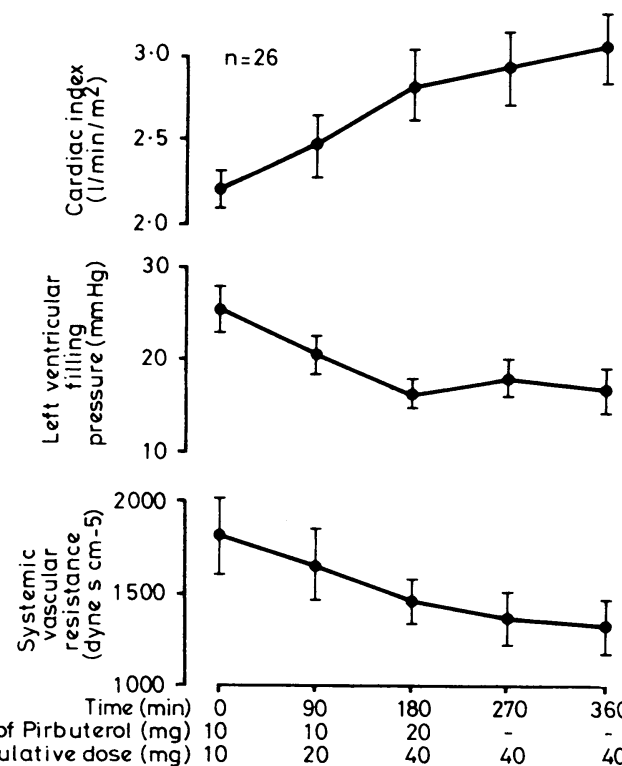

Cumulative dose (mg) 10

FIG 2-Changes in cardiac index, left ventricular filling pressure, and systemic vascular resistance with time in 26 patients (group 2) given incremental doses of pirbuterol. Dose of pirbuterol indicated at time of administration. (Plots are means \pm SEM.)

TABLE II-Values for all haemodynamic variables with time and incremental doses in 26 patients (group 2) (means $\pm S E M)$

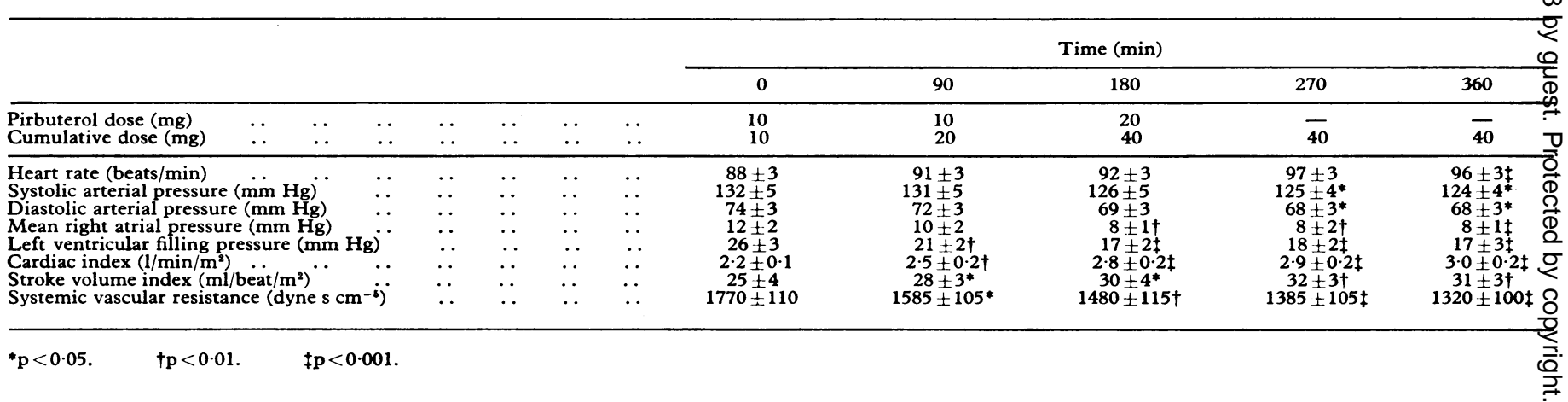


Plasma concentrations and haemodynamic changes-Plasma drug concentrations were measured in 12 patients in group 1 and 17 patients in groups 2 and 3 . In groups 2 and 3 plasma pirbuterol concentrations increased with incremental doses. In association with the increase in plasma pirbuterol concentration there was an increase in cardiac index and a fall in left ventricular filling pressure (fig 3 ). In group 1 the plasma concentration showed no difference between patients given either 10 or $20 \mathrm{mg}$ as a single oral dose. In this group haemodynamic changes correlated poorly with plasma concentration.
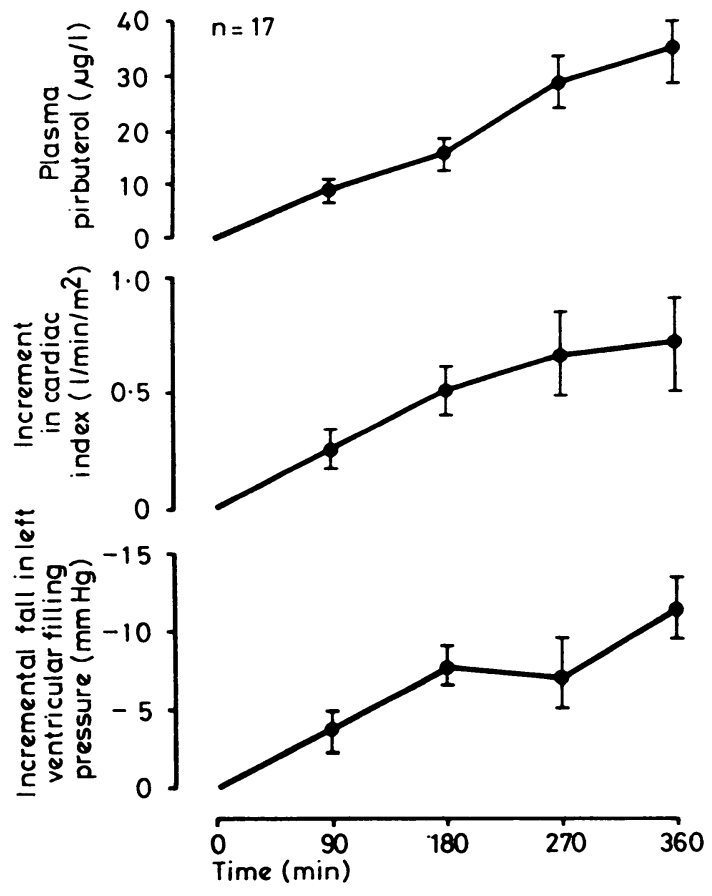

FIG 3-Changes in plasma pirbuterol concentration, cardiac index, and left ventricular filling pressure in 17 patients from groups 2 and 3 given incremental doses of pirbuterol. (Plots are means \pm SEM.)

Complications-No arrhythmias were detected. One patient in group 3 developed transient red-cell haemolysis and haemoglobinuria during the period of haemodynamic monitoring. No evidence was obtained to suggest that this was linked to the use of pirbuterol.

\section{Discussion}

This study shows that oral pirbuterol improves cardiac performance in severe chronic heart failure. Cardiac. index was increased and systemic vascular resistance and left ventricular filling pressure reduced. These changes were often accompanied by subjective symptomatic improvement. Only small falls in systolic and diastolic blood pressure were observed, and heart rate did not alter except at the highest dose. These results confirm initial studies with pirbuterol in smaller groups of patients. ${ }^{10} 11$

The haemodynamic effects of pirbuterol resemble those of salbutamol, which was studied in a similar though smaller group of patients. ${ }^{13}$ Comparison with other oral vasodilators shows that pirbuterol produces both substantial rises in cardiac index and falls in left ventricular filling pressure, whereas hydralazine (predominant action on arterioles) increases cardiac output but has only a minimal effect on left ventricular filling pressure. ${ }^{14}$ Isosorbide dinitrate (predominant action on venous capacitance vessels) reduces left ventricular filling pressure but has only a small effect on cardiac output. ${ }^{15}$ Prazosin has a more balanced action but may be associated with tachyphylaxis. ${ }^{10}$ The magni- tude of the haemodynamic response to incremental doses of pirbuterol varied with the plasma concentration. Incremental doses caused an increase in the plasma concentration. The results $\underline{\underline{G}}$ suggest that in most patients $20 \mathrm{mg}$ is sufficient to achieve a 3 maximal haemodynamic effect. Gold and Horowitz, ${ }^{9}$ studying $\stackrel{\odot}{\odot}$ the action of intravenous pirbuterol in normal dogs, observed a $C$ similar response with maximal effects being achieved by an $\widehat{\Omega}$ infusion of $2 \mu \mathrm{g} / \mathrm{kg} / \mathrm{min}$, higher doses having no further effect. $\bar{J}$ In our single-dose studies the plasma pirbuterol concentrations produced by doses of 10 and $20 \mathrm{mg}$ were similar, as were the ${ }^{\infty}$ haemodynamic responses. The reason for the similar plasma pirbuterol concentrations after different doses is unexplained. $\because$

We tried to identify those patients who might show the greatest benefit from pirbuterol. Figure 4 plots the incrementalo changes in systemic vascular resistance and left ventricular filling pressure against the initial values for all patients in the $\overline{\bar{c}}$ study. We had expected that patients with the highest systemic $\overparen{\otimes}$ vascular resistance and left ventricular filling pressure would show the greatest reduction in these variables. This simple ${ }^{\infty}$ concept was only partly borne out by the results (fig 4).
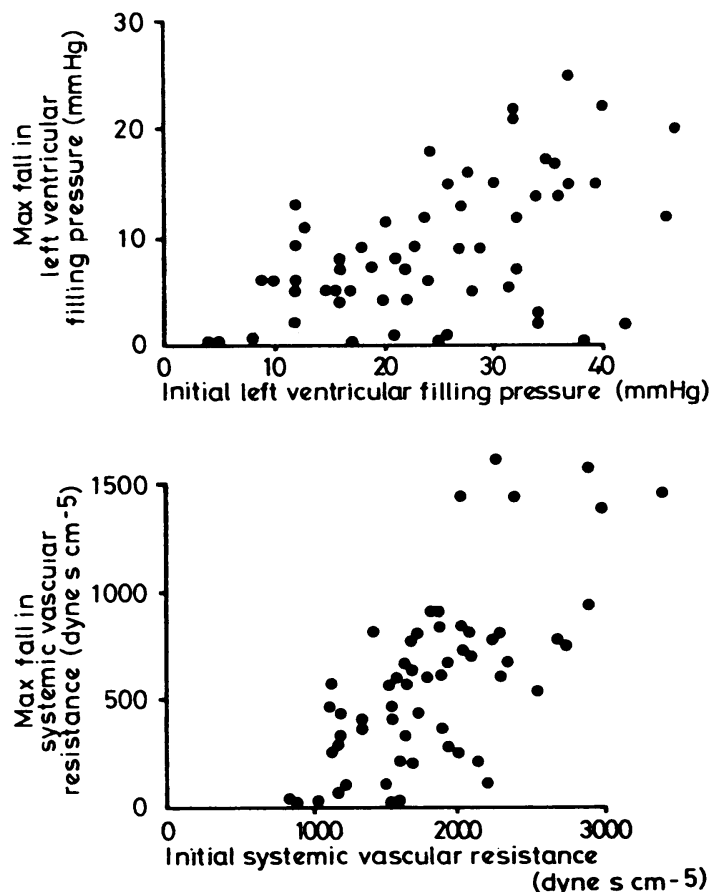

FIG 4-Individual falls in left ventricular filling pressure and systemic vascular resistance plotted against initial values $(n=59)$.

In clinical studies of patients with heart failure the mechanismon by which pirbuterol improves pump performance cannot be determined. Improved cardiac performance may be the consequence of a direct positive inotropic effect or secondary to an vasodilator effect or a combination of these two mechanisms. In our patients systolic blood pressure was reduced only by the highest dose of pirbuterol and a small reduction in diastolic bloof pressure occurred in all three groups. These changes are consistent with vasodilatation being the dominant mechanism rather? than a direct positive inotropic effect.

Experiments in animals ${ }^{\circ}$ (M L Hayden, unpublishedo observations) show that pirbuterol has both positive inotropic and vasodilator properties. In isolated preparations of guinea- $-\vec{D}$ pig tracheal muscle ${ }^{8}$ and dogs' hindlegs (M L Hayden) pirbuterob is a potent beta 2 agonist. Gold and Horowitz' showed in dogs that pirbuterol in addition to beta 2 activity has beta (cardiac) $^{0}$ agonist activity. Moreover, Hayden has confirmed that the drug is a potent inotropic agent in canine heart-lung preparations. 
Because pirbuterol brought about substantial acute haemodynamic benefits in most patients and is well tolerated and free from major side effects ${ }^{118} 53$ of these patients have been included in a trial to determine the long-term efficacy of pirbuterol in chronic heart failure.

We thank Pfizer Central Research for supplies of pirbuterol and for measuring plasma pirbuterol concentrations.

Requests for reprints should be addressed to: Dr G C Sutton, Hillingdon Hospital, Uxbridge, Middlesex.

\section{References}

${ }^{1}$ Chatteriee K, Parmley WW. Vasodilator treatment for acute and chronic heart failure. Br Heart $\mathcal{F} 1977 ; 39: 706-20$.

2 Cohn JN, Franciosa JA. Vasodilator therapy of cardiac failure. $N$ Engl f Med 1977;297:254-8.

${ }^{3}$ Stoner JD, Bolen BJ, Harrison DC. Comparison of dobutamine and dopamine in treatment of severe heart failure. Br Heart $\mathcal{f} 1977 ; 39$ : 536-41.

4 Akhtar M, Mikulic E, Cohn JN, Chaundhry MA. Hemodynamic effect of dobutamine in patients with severe heart failure. Am $\mathcal{F}$ Cardiol 1975; $36: 202-5$.

5 Benotti JR, Grossman W, Braunwald E, Vavolos DD, Alousi AA. Hemodynamic assessment of amrinone a new inotropic agent. $N$ Engl $\mathcal{f}$ Med $1978 ; 229: 1371-7$.

6 Miller RR, Awan NA, Joye JA, et al. Combined dopamine and nitroprusside therapy in congestive heart failure. Circulation 1977;55:881.
7 Mikulic E, Cohn JN, Franciosa JA. Comparative hemodynamic effects of inotropic and vasodilator drugs in severe heart failure. Circulation $1977 ; 56: 528-33$.

${ }^{8}$ Moore PF, Constantine JW, Bauth WE. Pirbuterol, a selective beta adrenergic bronchodilator. F Pharmacol Exp Ther 1978;207:410-8.

9 Gold FL, Horowitz LD. Hemodynamic effects of pirbuterol in conscious normal dogs. Clinical Research 1980;28:174A.

10 Sharma B, Hoback J, Francis G, et al. Pirbuterol : an oral beta agonist for therapy of congestive heart failure. Circulation $1979 ; 60,11: 229$.

11 Awan NA, Hermanovich J, Skinner P, Mason DT. Efficacy of oral beta, agonist pirbuterol in chronic heart failure refractory to digitalis. Circulation 1979;60,II :229.

12 Falkener FC, McIlhenny HM. Selected ion monitoring assay for the bronchodilator pirbuterol. Biomed Mass Spectrom 1976;3:207.

13 Bourdillon PDV, Dawson JR, Foale RA, Timmis AD, Poole-Wilson PA, Sutton GC. Salbutamol in treatment of heart failure. Br Heart $\mathcal{F} 1980$; 43:206-10.

14 Franciosa JA, Pierpont G, Cohn JN. Hemodynamic improvement with hydrallazine in left heart failure. Ann Intern Med 1977;86:388-93.

16 Williams DO, Bommer WJ, Miller RA, Amsterdam EA, Mason DT. Prolonged effectiveness of isosorbide dinitrate. Am $\mathcal{F}$ Cardiol 1977;39: 84-90.

${ }^{16}$ Packer M, Meller J, Gorlin R, Herman MV. Hemodynamic and clinical tachyphylaxis to prazosin mediated afterload reduction in severe chronic congestive heart failure. Circulation 1979;59:531-9.

17 Paterson IC, Willey RF, Grant IB. Effect of prolonged administration of pirbuterol by mouth in chronic asthma. Br $\mathcal{F}$ Clin Pharmacol 1977;4: 376-7.

18 Burki N, Diamond S. Long term oral bronchodilator therapy of asthma with pirbuterol (abstract). Clin Pharmacol Ther 1978;24:84-9.

(Accepted 26 February 1981)
ONE HUNDRED YEARS AGO SIR,-Truly he is a happy man -a happy doctor, I should say - who can honestly affirm that he never by his alcoholic prescriptions made a drunkard. For myself, in my earlier days, I was a firm believer in the many supposed virtues of alcoholic compounds. It is about fourteen years ago that the scales were removed from my eyes by the stern reality of facts, and my sole regret now is, that $I$ held out so long against evidence of the most startling kind.

Many years ago I asked a noted drunkard to sign the pledge, when she replied, bitterly, that I was the last man who ought to give her such advice; for it was my own father who had taught her to love the drink. He had prescribed whisky for her in an illness, and she had learned to love it. I did succeed for eighteen months; then she fell, through a publican.

A few months ago, an old lady, a former patient of mine, whom I had not seen for many years, said to me, "Doctor, I still, at times, suffer from that pain in my back which I had long ago; and I still take your prescription regularly, I assure you." "Indeed; pray, what was it ?" "A tumbler of gin toddy every night going to bed." I felt deeply ashamed. "My dear madam, that is twelve years you have gone on taking a medicine which has not yet cured you! Pray follow my advice now; give up the useless drug, and try something better." But did she ? I trow not. She had learned to like it, and she would have it; and her own sister says, sorrowfully, that she sometimes "takes more than is good for her"; in plainer words, she is a drunkard. And this by my prescription.

If there is one thing which disquiets my mind now, and will do so till my dying hour, it is the remembrance of cases such as this, where, by my blindly carrying out the teaching of my student days, I have brought mortal injury to both body and soul of those who trusted themselves in my hands. I have resolved to do all that in me lies to repair the mischief I so unwittingly have done; and in a few cases I am thankful to say I have succeeded in restoring to themselves one and another, who had been led into excess by my prescriptions. I was sent for to a lady supposed to be seriously ill. I recognised the cause of her illness, it was the result of my pernicious practice. I kept my own counsel, and was ultimately successful in prevailing upon her to cease taking the stimulant which was really the sole cause of her in disposition. In a similar case of a maidservant, $I$ had the happiness of undoing, as far as it ever can be undone, my own evil work.

Will Mr Baker object, as he has done to examples cited by Miss Richardson, that these are nameless cases ? Of course they are, they must be nameless. No medical man would be so dishonourable as to betray to the world the family secret confided to him. It is enough that I acknowledge the disastrous results of my belief in the popular delusion with regard to the prescription of alcoholic stimulants. I may just add, that I can very happily compare my present practice with that of the days when I prescribed alcohol right and left, as is still done by those who retain their faith in it. I am now convinced that stimulant does more harm than good, even in the complaint for which it is almost universally administered-weakness of action of the heart.

Some time after my change of system, a literary lady was placed for a while in my hands to recover from the effects of over-work. To her great dissatisfaction, I gave her no stimulant. She told me repeatedly that her London physician, "who knew her constitution perfectly," had always ordered it, and she "was confident that without it she should die"; and many a left-handed compliment I got for withholding from her, while in my house, what she loved so well. However, she got better without it, and returned to her home. She died in London a few years afterwards, separated from her husband-need I say for what?

I have said enough, I think, to prove that we medical men are verily guilty in this matter, and that no browbeating of those who venture to remonstrate with us will avail to clear us from the charge which they bring against us.

I would close with a word of warning to my brother medicos. In observing the results of this mode of practice, as I have had opportunity to do in the small towns in which $I$ have lived, $I$ have been distressed to see friends, and former fellow-students of my own, who, making the fatal mistake of following their own prescriptions, have themselves fallen victims to their mistaken theory.-I am, etc. J C REID, MD. (British Medical fournal, 1881.)

ONE HUNDRED YEARS AGO We are pleased to be able to congratulate $\mathrm{Mr}$ Cremer of Norwich, ex-medical officer of the union, on the success of his appeal for superannuation allowance, despite the memorial of the Ratepayers' Association to the guardians praying that such grant should not be made. If ever a medical officer merited such consideration from the board he had served, $\mathrm{Mr}$ Cremer was that one. Having reached the advanced age of eighty-four years, he has held his office uninterruptedly for fifty-one years. On the question being put to the vote, whether an annuity of $£ 50$ should be given, eighteen guardians voted for it, seven against, and four remained neutral; consequently the resolution was carried. Similarly, we have to express our sympathy with $\mathrm{Mr}$ George Pink, eighty-seven years old, who has held office in the Petersfield Union for over forty years, and who, having been compelled to resign his appointment in consequence of advanced age, finds himself in very straitened circumstances. Here his application was not even entertained. (British Medical fournal, 1881.) 